\title{
Analysis of the written handover process during shift changes within the hospital
}

An ergonomic evaluation of the use of a new writing format

Jean-Michel Boucheix and Michèle Coiron

\section{(2) OpenEdition}

\section{Journals}

Electronic version

URL: http://journals.openedition.org/activites/1963

DOI: 10.4000/activites. 1963

ISSN: $1765-2723$

\section{Publisher}

ARPACT - Association Recherches et Pratiques sur les ACTivités

\section{Electronic reference}

Jean-Michel Boucheix and Michèle Coiron, « Analysis of the written handover process during shift changes within the hospital », Activités [Online], 5-1 | avril 2008, Online since 15 April 2008, connection on 30 April 2019. URL : http://journals.openedition.org/activites/1963; DOI : 10.4000/activites.1963

\section{(c) $)(9)$}

Activités est mis à disposition selon les termes de la licence Creative Commons Attribution - Pas d'Utilisation Commerciale - Pas de Modification 4.0 International. 


\title{
Analysis of the written handover process during shift changes within the hospital: an ergonomic evaluation of the use of a new writing format
}

\author{
Jean-Michel Boucheix \\ University of Burgundy, LEAD/CNRS, UMR 5022, Pôle AAFE, Esplanade Erasme, 21065 Dijon, BP : 26513 \\ Email: Jean-Michel.Boucheix@u-bourgogne.fr.
}

\section{Michèle Coiron}

C.H.U, Nursing Supervisor, Training Manager.

\begin{abstract}
This study assesses the ergonomic quality of a new writing format used for the written transmission of activity during a nurse's handover in a hospital. This format called "targeted or focussed transmission" comes from a new prescription of hospital management designed to improve the written handover process. Our research focused on the information filtering process for each patient concerned by a shift handover. A three step methodology was designed, with the participation of 9 nurses in charge of 70 patients: (1) nursing work analysis before the handover, (2) oral handover analysis, (3) written handover analysis. Results show that the new writing format does not match the nurses' needs to perform high quality handovers. The main clues, clinical signs and patient behaviour, used by nurses during an oral handover, to supervise the monitoring of the patient state disappear from the content of the written handover document. Regulation activities carried out to manage areas of dysfunction within the patient's state, which are a main topic in the oral handover, are not included in the written handover document. The different roles played by oral dialogue and written traces in the patient monitoring activity have been analysed and discussed. Finally, a cognitive model of professional written production is proposed and discussed and also some recommendations to design writing tools for the optimization of written handover documents.
\end{abstract}

KEYWORDS

Working relief, Written transmissions, Written production model.

\section{1.- Introduction}

Via an analysis of handover activity between nurses at change of shift, the aim of this study is to assess the ease of use of a new format for writing written handover documents designed and ordered by the hospital. In a context of optimising the "quality" of patient care, many hospitals wish to meet accreditation criteria governing healthcare establishments. This approach prescribes the use of indicators to keep a trace of care provided. These are associated with a requirement for "increased efficiency" in the context of reducing hospital costs and an increase in short-term admissions and discharges linked to the increasing use of medical investigation technology. In short, the information load is growing, while context sensitive data concerning patients is reducing. In this context, the CHU (in a city of 250,000 inhabitants) designed and developed, in partnership with nursing managers, a new formal text structure for written handover documents for use by nurses when changing shifts. The purpose of so-called "targeted" handovers is to focus what is written about each patient on a target, that is to say on pertinent information from the last shift, then to develop information concerning this target according to a formal structure based on three criteria: Data, Actions carried 
out and Results obtained (D.A.R., cf table 1 and below). The purpose of these new instructions was to ensure better and more accurate monitoring of patients' condition in real time by selecting significant aspects of the development of the patient's condition (dynamic system, Cellier, de Keyser, \& Valot, 1996 ; Hoc, 1996). In this way, daily visible and traceable changes in a patient's status could be monitored "on-line", thus reducing the risk of post-operative incidents as much as possible.

The design and use of this new "writing tool", used in the CHU involved in this study, was carried out before our intervention, without any prior analysis of the existing normal process used by nursing staff in writing up spontaneous notes. However, nursing staff have a long practice of delivering handover information and the question can be asked as to whether this new format was suited to the nurses' real needs. For the institution, the reason for implementing this new format seems to be twofold: to provide written traceability of nursing care and to create a document that would help with writing up accurate handover notes. Does the proposed handover format meet these objectives? Faced with the difficulties reported by nursing staff subsequent to the introduction of this new method, the hospital's initial request to us had been to set up a professional training course aimed at developing nurses' skills in writing up this specific, so-called "targeted" written handover format.

Before considering any sort of training activity, we felt it was necessary, at the ergonomic level, to check the suitability of this recording tool in relation to nurses' handover activity during the change of shift (de Montmollin, 1986 ; Rogalski, \& Samurçay, 1994 ; Leplat, 1997 ; Pastré, 1997 ; Boucheix, 2003). The objective of the work presented in this article is to evaluate the ergonomic suitability of this new format of writing up the written handover notes prescribed by the hospital as compared with the needs of nursing staff involved in the handover. In order to do this, we analysed the oral and written handover activity on change of shift of nine nurses in charge of seventy patients. This analysis was preceded by a study of the period of activity with these patients prior to handover. We paid particular attention to the dimension of filtering information. At the end of our study we will make recommendations for optimising these written notes.

\section{1.-What is targeted handover, D.A.R.? Analysis of the instructions}

Our goal is to evaluate the use of targeted written notes, but what is a so-called «targeted» written handover? In this part, we will first of all introduce the benefits that were expected by the hospital from the implementation of targeted handovers and provide an analysis of the constraints inherent in this new instruction.

Firstly, targeted handover (see the example presented in table 1) involves sorting information concerning a patient's progress. This sorting requires choosing a target that corresponds to new and pertinent information concerning the patient and developing this target with clinical information concerning that patient. This target is chosen by the nurse. Around a main theme called the target, information describing this target must be classified according to three criteria: Data, Actions, Results: D.A.R. An example of the change between a "normal" handover (taken from our sample) and a targeted handover is presented in table 1 .

Handover prior to targeted handover

\begin{tabular}{|c|c|c|c|c|}
\hline Date & Name & \multirow{2}{*}{\multicolumn{3}{|c|}{ Was in pain at the beginning of the night, soothed by Prodaf, hardly slept }} \\
\hline $6 / 04 / 98$ & $\mathrm{X}$ & & & \\
\hline \multicolumn{5}{|c|}{ Targeted handover } \\
\hline Date & Name & Target & DAR & \\
\hline \multirow[t]{2}{*}{20.00} & $\mathrm{X}$ & Pain & D & $\begin{array}{l}\text { Intense abdominal pain, antalgic position with legs } \\
\text { tucked up, groaning. }\end{array}$ \\
\hline & & & A & Injection of Prodalfon et Spasfon. \\
\hline 21.00 & & & $\mathbf{R}$ & patient calmed, no longer complaining. \\
\hline
\end{tabular}

Table 1: Example of targeted handover in D.A.R (Data, Actions, Results) format 
According to the instructions, the criteria for choosing the target corresponds to the "occurrence of a physiological or psychological event, of a condition or sensation that was not present and which changes the patient's status". This choice appears over-simplified. It involves sorting information memorised during care. Two types of criteria determine this selection. The first concerns pertinence, that is to say the pertinence and newness of the information supplied as compared with the pathology and the expected prognosis for improvements in the patient's health. Once a choice has been made in this dimension, nurses must change from their normal way of recording information, that is to say, following an order that conforms to their spontaneous retrieval of memorised information (chronological, as in the example in table 1: "Was in pain at the beginning of the night, calmed by Prodaf ..."), to a way of organising written information following a classification according to a list or new categorisation. The development of information concerning the chosen target must be carried out according to the formal DAR structure. From the operational point of view, it is not certain that this new format is actually more functional than the one used spontaneously by nurses. The only addition, is an "institutional" standard of acceptability covering what can be written as compared with what can be said during oral handover.

Targeted transmission also has the aim of improving the accuracy of clinical information. In the following example, the information "suffered all night" would be expanded more accurately as follows "abdominal pain, antalgic position with legs tucked up, groaning". This clarification could provide information likely to optimize diagnosis and help with the anticipation of future events. These so-called "nursing" diagnoses correspond to a clinical judgement (diagnosis and prognosis) concerning the patient's progress, serving as a basis (as a supplement to the medical prescription) for the choice of care implemented by nursing staff. This analyses the patient's reactions to the doctor's prescription, anticipates behaviours creating risk, and regulates the patient's condition (comfort, well-being). This activity, on which the preparation of the written handover is based, is based on noting "clinical signs" and a reasoning process (relating the signs to prior knowledge, followed by a hypothesis). Decisions governing action may then be envisaged. An example of a possible development in a diagnosis of this type based on clinical signs is given in the following example:

Current diagnosis, based on signs:

"Anxiety linked to hospitalisation is shown by a trembling voice".

Potential diagnosis, based on risks:

"Infectious risk linked to a deterioration in the immune system".

Let's note however that in the example in table 1, the spontaneous description "Was in pain at the beginning of the night, calmed by Prodaf, hardly slept" also contains information more centred on the patient's experience and his/her relationship with the latter, while the targeted handover has more to do with a technical diagnosis "Intense abdominal pain, anatalgic position with legs tucked up, groaning, Injection of Prodalfan and Spasfon. Patient calmed, no longer complaining". Thus, the relationship and contact with the patient constitute fundamental aspects of the business of providing care.

During targeted handover, it is also important to avoid repetition. Targeting information reduces major redundancy in what is communicated at handover from one shift to the next. However, it should be noted that sometimes this redundancy could be useful. A standardized presentation makes finding information easier. The distribution of information developed according to the formal DAR structure should optimize classification of information and make retrieving it easier, as long as nurses make use of the tool.

Finally, due to the traceability objective sought by the institution, DAR could cause nursing staff to evaluate the "acceptability" of the information developed. In fact, a written trace makes the information permanently accessible to several categories of recipients. This written record also promotes standards of acceptability concerning the type of information chosen, which may be different from the information shared at an oral handover.

In short, writing up a targeted handover will involve the following constraints: filtering and sorting information, improving the content of clinical descriptions, incorporating nurses' diagnoses, avoid- 
ing repetition from one shift to the next and easier retrieval of information than in the case of unstructured notes. In this sense, they constitute a series of descriptions of the development of a patient's status, comparable to a "dynamic system" (Hoc, 1996). But is this standardized format suited to a nurse's activity?

\section{2.- Difficulties encountered in implementing targeted handover, DAR.}

The objective set by the institution during the introduction of a written handover procedure was to "capitalize on reliable and practical information to ensure continuity of care" (text prescribed by the accreditation process). The purpose of these new instructions was for nursing staff to operate a dynamic system of care represented by the patient in relation to the doctor. But nurses, in particular experienced nurses, have already been using operational monitoring and handover skills via written media for a long time (care notes, monitoring sheets, normal written handover) as well as oral methods (oral handover) (cf. Errard, Kostulski, \& Trognon, 1996). Nurses already sort information in their normal written practice as shown by the example in table 1. It is during these activities that the specific skills of "nursing diagnosis" are developed.

Works devoted to hospital care and in particular to oral handover have shown that professionals effectively develop a true intelligence and a true collective competence (Cosnier, Grosjean, \& Lacoste, 1993 ; Grosjean, \& Lacoste, 1999). In addition, shift change is not just reduced to a unilateral handover of information, it represents a constructive interaction between the people involved during which problems are analysed and resolved (Grusenmeyer, 1995, 1996 ; Grusenmeyer \& Trognon, 1996) as in interactions in service situations (Cerf, Valléry, \& Boucheix, 2004 ; Falzon, 2004 ; Boucheix, 2005 ; Cerf \& Falzon, 2005 ;Valléry, Leduc, Boucheix, \& Cerf, 2005 ). Grosjean and Lacoste (1999) have shown that written and oral handover represent two complementary methods of patient care, serving two different purposes.

From their perspective, works on cognitive psychology concerning the production of language have also shown that oral production (or interaction) and written production constitute two methods of working. The functional constraints of both methods are distinct (Bourdin, 1994 ; Heurley, 1994 ; Fayol, 1997 ; Alamargot, \& Dansac, 2003). In the one case, the recipient is present and is simultaneously active in the context of a multimodal communication accompanied by various forms of feedback that help build a common repository (Giboin, 2004), in the other case, the recipient is absent. Targeted handover requires the writer to manage two types of constraint. From the point of view of writing, it represents a transition from the normal spontaneous recording of knowledge arising directly from the action which corresponds to a strategy of retrieving knowledge from memory alongside the writing process (Fayol, 1997) to a presentation of information organised around chosen themes (from others that are possible) and according to a prescribed method of organising the text. This second method involves using a strategy of "processing" knowledge ( Levelt, 1989 ; Levelt, \& Maassen, 1991 ; Hayes and Nash, 1996 ; Fayol, 1997), according to a goal and a recipient. Bourdin (1994) showed that this type of processing activity was particularly difficult. In addition, constraints of the social-institutional type come into play in writing written care reports (Boutet, 1995): type of recipient, use and status of the written record, and an underlying evaluation of professionals' activity via written reports. In all these cases, operative language is used (Falzon, 1989), but it is written and not a lot is known about written operative language.

This new written instruction is addressed to all CHU's nurses. During its design, which preceded the request made to us, no prior analysis was made of the professionals' activity or the acceptability of the new tool. Only information was given. Before the planned generalisation to the whole CHU, several departments studied here had already adopted the practice of DAR type targeted handovers. During our exploratory interviews, the nursing staff concerned reported difficulties in the spontaneous use of a written targeted handover procedure, while at the same time expressing the wish to improve handover. 
We started by conducting a first phase of direct exploratory observation of the nurses using the targeted handover approach (direct interviews concerning what was written and the observations involved) in order to confirm there really was a problem. We were in this way seeking a better understanding of how nurses defined the notion of a target and what it represented to them. We were able to uncover the following difficulties:

- Even if the objective of a written handover is not to act as a substitute for an oral handover but to supplement it, too great an amount of information was lost between the oral and written parts of the handover process, which poses the problem of selection.

- The choice of target (categorisation) and formulation (in DAR format) often pose a problem. The effect of this difficulty was that staff fell back on "generic" targets resulting not from the identification of clinical signs, but from the use of a generic classification that is traditional in the nursing profession but which does not convey a great deal of information concerning the development of the patient's condition. For example: "feeding", "breathing".

- Finding precise information, which is not always accessible at the time of writing, may generate bias concerning the reality of data related about a patient.

- Organisation of information does not follow the DAR structure. For example, the result of taking blood pressure may be classified as data or a result, for the same target: "risk of hypertension".

- It is difficult to distinguish an action that should be considered from one that has already been carried out. For example: "should continue to fast" and "humidification stopped"

- The results of actions carried out by the nurse, which are the real markers for monitoring the development of the problems encountered, are often missing from the written record.

- Accuracy of information reported varies a great deal both between individuals and by one individual themselves (qualitative and quantitative).

In short, expressing nursing care via a targeted handover process seems difficult. The objective of this work is to evaluate the suitability of targeted handover to the nursing shift changeover process. With this in mind, we analysed the written handover activity as carried out by a number of nurses using this new scoring system with regard to their supervision of the development of patients' conditions. In particular we focused on the process of filtering pertinent information concerning patients' development.

- Is targeted handover used and how?

- To what extent does this written format contain and preserve a trace of nurses' real care activity (diagnosis, prognosis, risks, incidents, regulations)?

Conversely, what information originating from nursing activity is not included in this handover process?

- What are the cognitive processes used when writing the handover? What is the function of this targeted handover in comparison to an oral shift change of shift?

The way these questions are answered potentially gives a very different direction to recommendations.

\section{2.- Method}

Given the difficulties expressed above, what significant traces of nursing activity should be contained in targeted handover? And in particular, will they preserve any trace of nursing diagnosis that may prove crucial with regard to patient care? The test of this hypothesis requires an ability to compare the content and form of the written documents with the content and form of other nursing activities with regard to patients that is the subject of these written documents: in particular the content of oral handover and the content of the nurse's knowledge and descriptions concerning each patient present 
and resulting from activity that preceded the change of shift. From this comparison, it is possible to deduce both the existence of traces (written and named) of nursing activity and the type of care goals actually used in order to produce this written professional document. In fact, at the time of writing up the handover in the new format, nurses must make a "calculation" in order to choose, then process and put into words the product of selecting information, this "calculation" depending on descriptions memorized by nurses while providing care and during the oral handover (this latter being in general carried out previously), constraints linked to the potential recipients of this written record, and constraints inherent in the writing process.

\section{1.- Subjects}

We sought out nine nurses involved in producing written targeted handover documents on a daily basis, taking account of a variable that could prove to be sensitive to this handover activity, namely expertise. The distribution is as follows: three experts recognized by their peers for the quality of their handovers (with at least 10 years experience in different departments), four novices (with between one and less than three years experience in different departments) and two professionals with "intermediate" status (over three years experience in different departments) but regarded as being experienced. Three different departments were approached (medical, neurology and nephrology) which were comparable as far as the seriousness of the pathologies encountered (operations) were concerned.

\section{2.- Approach and procedure}

We followed an approach in three chronological phases presented in table 2. This approach is based on establishing a relationship (comparison) between the actual activity of each outgoing nurse (with each patient), observed just before oral and written handover at the change of shift for the same patients during the work cycle. The incoming nurses, the beneficiaries of this handover, had been absent for less than one to three days.

\begin{tabular}{|c|c|c|c|c|}
\hline Progress & Phases & Objectives & Process studied & Result / Filtering \\
\hline \multirow{3}{*}{$\sum_{\boxminus}^{\Perp}$} & $\begin{array}{l}\text { Phase } 1 \text { - Analysis of } \\
\text { activity prior to the } \\
\text { written handover } \\
\text { (70 patients, } 9 \\
\text { nurses) }\end{array}$ & $\begin{array}{c}\text { Individual reference } \\
\text { representation } \\
(\mathbf{R R}) \text { previously } \\
\text { memorised for each } \\
\text { patient }\end{array}$ & \multirow{3}{*}{ 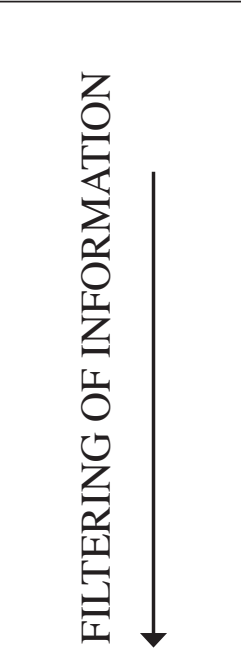 } & $\begin{array}{c}\text { Knowledge } \\
\text { and reference } \\
\text { representations (RR) }\end{array}$ \\
\hline & $\begin{array}{c}\text { Phase } 2 \text { - Analysis of } \\
\text { oral handover }\end{array}$ & $\begin{array}{c}\text { Information } \\
\text { communicated } \\
\text { during the oral } \\
\text { handover }(\mathbf{O H}) \\
\end{array}$ & & $\begin{array}{c}\text { Comparison } \mathbf{C R} \text { and } \\
\mathbf{O H}\end{array}$ \\
\hline & $\begin{array}{c}\text { Phase } 3 \text { - Analysis of } \\
\text { written handover }\end{array}$ & $\begin{array}{l}\text { Written production } \\
(\mathbf{W P}) \text { Information } \\
\text { and transcription } \\
\text { process }\end{array}$ & & $\begin{array}{c}\text { Comparison } \mathbf{C R}, \mathbf{O H} \\
\text { and } \mathbf{W P}\end{array}$ \\
\hline
\end{tabular}

Table 2. - Methodology and chronology of the analysis of the written handover activity

The aim of the first phase (table 2) was to constitute a database of knowledge and reference representations concerning the content of each patient's care for each nurse. This reference reflected the descriptions previously memorized for each patient by each nurse at the time of preparing the oral handover then the written handover. This Phase 1 was carried out with an analysis of prior activity. It represents direct observations and records made on the job: we made direct observation of the 
care actions, behaviour and interactions of each nurse in a real-life situation, accompanied by audio recordings (wireless microphones) of each interaction (with the patient or a colleague) for each nurse (for a total of 81 hours). All the actions of each nurse were recorded, the shift preceding the care cycle, interactions with each patient, the shift following the care cycle, oral and written. These observations and recordings were then fully transcribed. The categories of care with the nurse's aim were recorded precisely for each action: distribution and taking of medicine, taking and measurement of blood pressure, requests for information, daily care (bandaging), and the contents of information exchanged with the patient.

There followed an individual interview and recall session concerning the memorized descriptions, conducted just after the direct observations. The aim of this test was to transcribe as exhaustively as possible the descriptions and knowledge memorized by the nurse concerning the pathology and progress of each patient. Nursing staff were asked to make a distinction between, on the one hand, descriptions prior to the day the observations were made, and on the other hand, those resulting from the period of observation. This interview and recall session took place two days after the observation. In order to facilitate retrieval of descriptions for each patient, nurses had documents concerning each patient (care forms and prescriptions) and written notes of records made during the preceding observation.

Although the data recorded constituted rich material for detailed analysis, the use of the data from this phase did not constitute a complete analysis of care prior to the change of shift, but rather a medium that then permitted rigorous collection of nurses' descriptions concerning the patients. This summary was better suited to the limited comparison objectives of this study.

The aim of the second phase was to analyse written handover for each nurse observed with regard to the 70 patients for which nursing staff were responsible during the preceding activity (phase 1). The distribution of these patients was as follows: 23 for the novices group, 22 for the experienced group and 30 for the experts. Seventy changes of shift were recorded, for all the patients and nurses in the sample. The statements resulting from the complete re-transcriptions were then analysed.

The third phase had to do with the written handover documents. Its objective was to analyse the contents and the process of production of handover documents for the same 70 patients, by the nine nurses. We took a particular interest in the traces of care activity provided by the nurse for each patient, and the mechanisms used for transcribing these traces within the framework of the formal DAR structure. Seventy written handovers were collected, fully transcribed then analysed, corresponding to the same patients as the observations and the oral handover process. Then, in order to collect information concerning the writing rules and the process of producing the written documents, for each written document, on the day following handover and for each nurse, we conducted an interview where the nurse could provide an explanation concerning each of the handover documents he/she had written. This verbal protocol type technique, adapted from Bisseret, Sébillotte and Falzon (1999) was conducted with the written supporting medium in front of the nurse for each handover document and lasted about two hours per professional. The criteria used for analysing the data gained from the techniques used for each phase are then described in the results presentation.

Finally (last column in table 2), the data from the three phases in our approach is compared. The purpose of this comparison was to clarify the process used for "filtering" information, for the same nurse, starting with the reference representations (RR), then oral (OH) and finally written (WP) handover. Of course, the exchanges of information and the interactions cannot be reduced to this process of filtering expressed in the form of an "equation" in table 2. However, a study of this filtering process constitutes an important dimension for examining the information finally selected and retained during written handover. 


\section{3.- Results}

\section{1.- Phase 1 - Analysis of the observations: prior reference descriptions}

The purpose of this work was focussed on the process of producing written documents. As a consequence, our objective in describing the results from this first phase was not to give a detailed presentation of the data gained from 81 hours of observing each professional. Rather, it was a question of creating a database of reference descriptions for each patient in order to provide a better understanding of the type and filtering of information present in the written handover documents which will be analysed in detail in phase 3. We will limit ourselves therefore in presenting the results of this first phase, to an exposé of the care activities on the one hand, and the extent (quantitative) of knowledge memorized on the other hand, and finally, the themes and main sources of the reference descriptions concerning each patient, comprising representations of situations prior to the change of shift.

We will make brief reference to the results of the observations, then those of the interview and recall session knowledge test.

\section{The activities observed were as follows:}

- the sequence of planned care, according to a precise timetable: taking blood samples, checking blood pressure, medicines, injections.

- individual care linked to the patient's progress: help with toileting, preoperative preparation, bandaging, comfort.

- activities with regard to unplanned care: change in patient's status, results of examinations.

- verbal interaction with each patient alongside care referred to previously, focussing more on the experience and relationship with the patient.

- interactions with colleagues and actions carried out outside the patient area (forms to be filled in, for example).

- handover activities, oral and written transfer of information, during the change of shift. These latter lasted a minimum of 30 minutes per shift. Oral handover was generally collective, written handover individual. Written handover was carried out for each patient before oral handover for seven nurses out of 9, in the course of care for one nurse and after the oral handover for one. We also observed a great variation in the order information was recorded in writing: some nurses started with the targets before developing them, others started with the information and then wrote down the target. Other nurses read the previous written handover document, while others, the majority, did not.

Thus, the descriptions memorized by the nurses were the result of the following care activities:

- the activities observed and recorded above.

- verbal and non-verbal information recorded: visual and proprioceptive.

- the actions carried out which were most often the result of medical prescription.

- actions to deal with and regulate a problem experienced by the patient.

The amount of professional information obtained, through the frequency of interaction (verbal or non-verbal) with patients, which is one of the indicators linked to the quantity of prior knowledge memorized for each patient differs greatly depending on the level of expertise. In fact, the average number of interactions per patient is significantly higher for the experts ( 7.9 for 238 interactions with 30 patients) than for the novices (5.5 for 127 interactions with 23 patients) and for the experienced practitioners (4.6 for 102 interactions with 22 patients) $\left(\mathrm{Chi}^{2}=20.91, p<.01\right)$. As the rate of interaction is higher for the experts, we can assume that previously memorized knowledge is greater and/ or more accurate among these professionals. Of course the amount of knowledge (and interactions) is not necessarily indicative of its pertinence, nor of its function or content. But works on cognitive ergonomics concerning medical diagnosis show that this indicator of quantity is extremely useful. 
Quantity, and above all flexibility of operative descriptions, constitute critical dimensions of medical and caring competence (Raufaste, 2001).

What are the reference representations that result from the interview and recall session test? Verbal data from this test for each nurse was transcribed. We then categorized each statement (proposition or group of propositions linked to a theme), according to the type of source of the information concerned. These sources $(\mathrm{S})$ number seven in all:

- S1- Verbal interaction with the patient (eg: "for the 14.00 care. I said "hello", he didn't reply ...it's a way of evaluating their consciousness ... for someone who was supposed to be better, I found he didn't respond much").

- S2- Observation of clinical signs and behaviour during verbal or non-verbal interaction (eg: "when I took him to the scales, I felt he didn't want to push the drip stand, it was a problem to him").

- S3- New information at the change of shift (eg: "the night nurse told me ... that she had removed her drip")

- S4 - Knowledge prior to the day of observation (eg: "she had a problem with thoracic pain, ... she had an electro cardiogram, a cardiac assessment which showed nothing").

- S5 - Execution of the medical prescription (eg: "I was responsible for monitoring ... after the arteriogram ... normal blood pressure, good pulse").

- S6 - The patient's intrinsic pathology (eg: "she presented as ethylic with 3 grams ...").

- S7 - Independent actions (eg: "In relation to his infusions, I got him to have a mouthwash").

- This categorization will serve as a reference database in analysing information contained in the oral, then written, handover documents.

\section{2.- Phase 2 - Oral handover}

What is the content of the oral handover? This is the question we attempted to answer by the analysis conducted on the body of 70 oral handovers. In order to do this, we broke down each handover into smaller units: the turn, the statement, and the sequence. The turn is a general indicator of the density of the communication. We recorded 617 turns for all the patients, that is an average rate of 8.1 turns per patient. A statement corresponds to a complete unit of information on a theme, close to a proposition. A sequence is composed of a group of coherent statements concerning the same theme. It constitutes a good indicator of the goal contained in the themes tackled via the statements.

\subsection{1.- The themes tackled in statements during exchanges.}

\begin{tabular}{|c|c|c|}
\hline Theme of the reference & $\%$ & Categorisation example* \\
\hline Medical prescription & 34 & \\
\hline Behaviour & 18 & \multirow{8}{*}{$\begin{array}{l}\text { "Opposite, Mrs S (identity**) who was operated on for a chronic } \\
\text { sub-dural haematoma (medical diagnosis) who really isn't too bad } \\
\text { (overall clinical sign). She is still on a drip (prescription) and if she } \\
\text { eats well there won't be a problem in getting her to eat (behaviour). } \\
\text { She has a neuro deficit (clinical sign), it's just that she's a woman } \\
\text { who is insulin dependent (pathology) who has a dextro every four } \\
\text { hours (prescription)." }\end{array}$} \\
\hline Clinical signs & 16 & \\
\hline Diagnosis & 9 & \\
\hline Reason & 6 & \\
\hline Identity & 4 & \\
\hline Pathologies & 4 & \\
\hline General organisation & 4 & \\
\hline Miscellaneous & 4 & \\
\hline
\end{tabular}

Table 3 - Distribution (in \%) of different reference themes in oral handovers 
We recorded 1184 statements, in 70 handovers, that is an average of approximately 17 statements per handover. We classified each statement according to its subject, that is to say the theme of the information concerning the patient. The quantitative results of this classification are recorded in table 3 , as well as an example of the categorisation carried out.

We noticed that three types of information predominate. Those containing the medical prescription and its implementation, those to do with behaviour, and those to do with clinical signs that appear. These two last categories, clinical signs and behaviour represent $34 \%$ of the statements. They correspond to the real indicators of nursing care and risk management. In fact, these indictors (clinical signs in particular) concern modifications and changes in the patient's condition, based on a knowledge database structured by the initial medical diagnosis, the prescription and the reason for admission to hospital. In addition, these indicators seem to be expertise sensitive. Expert nurses made statements linked to the appearance of clinical signs or behaviours more often (40\%) than novice nurses $(29 \%)$ or experienced nurses $(31 \%)$. Conversely, novices took the medical prescription into account first (40\%) as compared with the experts (32\%). The other types of statement (patient identity, reasons for hospitalisation, organisation) were divided equally among the levels of expertise. In short, a study of the statements shows that oral handover covers a function of exchanging operative representations of changes of condition (clinical signs and behaviours) and their possible development in the patient.

\subsection{2.- Nurses' goals in the handover sequences}

Each sequence ( 247 in total) was characterised according to three criteria. The first concerned the nature of the situation described, which could be normal (containing for example the statement regarding the prescription) or deal with a problem in the patient's condition (change of condition or patient behaviour). The second criteria had to do with the subject tackled in six themes: medical prescription, known patient pathology, effects of the prescription, behaviours and clinical signs. The third criteria was to do with the level of regulation of the situation described. Four levels were defined: regulation carried out, regulation to be carried out, problem with regulation, absence of regulation. Regulation was said to have been carried out when the nurse indicated that after the remedial action or adjustment to the prescription, the patient recovered his/her condition prior to regulation. In the case of a regulation to be carried out, the handover contained the pertinent solution to be carried out on the patient as well as the procedure to follow, but the corresponding action had not yet been implemented at the time of the change of shift. A problem with regulation corresponded to a situation where after a problem had arisen in the patient's condition, the various remedial solutions tried had failed up to the time of the change of shift. Finally, absence of regulation corresponded to a situation where remedial actions to be carried out had not been (or could not be). There follow two examples of these situations: a problem to be regulated - "she has a cathlon in her hand. Taped. Should be monitored since she took it out, she has already removed cathlons, she was not really with us, I would say apathetic"; absence of regulation (or failure): "must drink, I didn't give her enough".

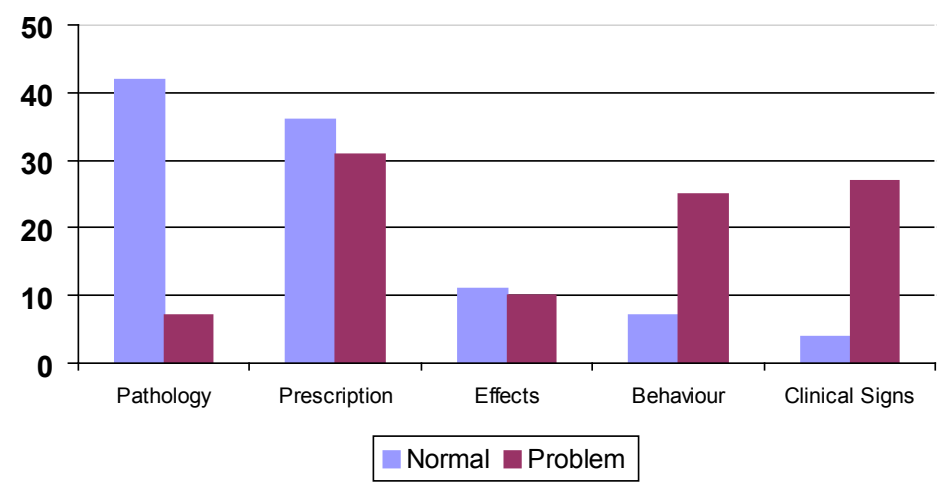

Figure 1 - Distribution (in \%) of sequences of oral handover by themes (Pathology, Medical prescription, Effects of the prescription, Behaviour, Clinical signs) according to type of situation (normal or with a problem). 
Of the 247 sequences analysed, $49 \%$ had to do with a normal situation, against $51 \%$ that concerned a problem. In figure 1 we demonstrate the distribution of sequences by theme and according to type of situation (normal or abnormal).

It appeared that the highest rates of problems concerned three indicators: prescriptions, clinical signs and behaviour. While a problem to do with the prescription may correspond for example to an adjustment to the prescription individual to the patient, the clinical signs and behaviour categories were critical indicators relating specifically to the problems in the patient's state of health which appeared in oral handovers. It's the regulation of these problems, not necessarily linked to the prescription, that is at the centre of exchanges in the context of the oral handover. The distribution of the categories of problems seemed to be different according to the level of expertise as shown in figure 2.

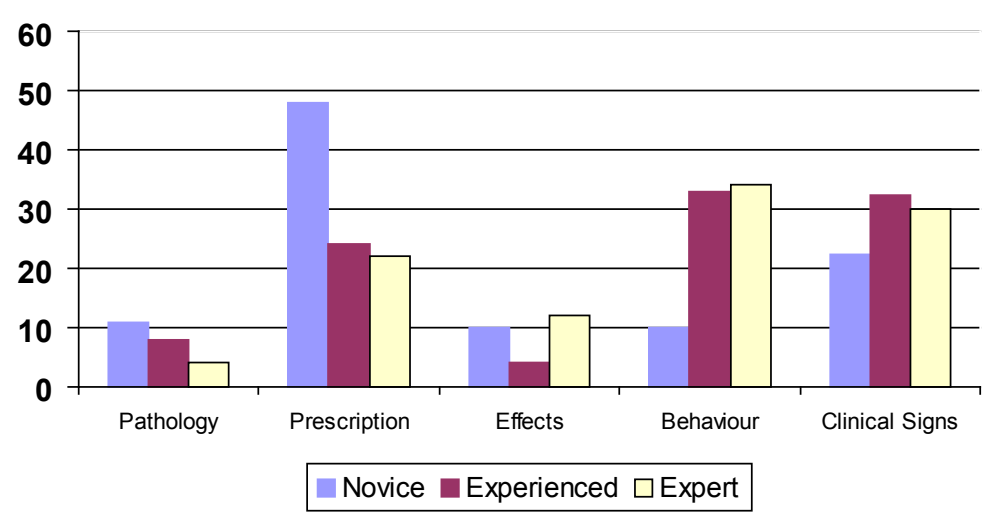

Figure 2 - Distribution of problem subjects according to the level of expertise

The experts, as well as the experienced professionals, exchanged much more information linked to clinical signs and behaviours than the novices did who were more focussed on the prescription. Thus, information pertinent to the handover is above all the first, which constitutes a trace of the patient's care and supervision provided by the nurse. It should be noted that this statistic indicates a trend since the data concerning the three levels of expertise does not relate to the same pathological situations.

\subsection{3.- Regulation as an issue in oral handover}

What is the level of regulation expressed in oral handover? We indicated above, the four possible stages of regulation. The distribution of oral handover sequences comprising a reference to a problem, according to these four levels, is presented in table 4.

\begin{tabular}{|c|c|}
\hline Level of regulation & Frequency in \% \\
\hline Regulation carried out & 49 \\
\hline Regulation to be carried out & 29 \\
\hline Problem with regulation & 12 \\
\hline Absence of regulation & 10 \\
\hline
\end{tabular}

Table 4 - Distribution of the different levels of regulation referred to during oral handover

It thus appeared that $\mathbf{5 1 \%}$ of problems were not yet regulated. Reference to them during oral handover gives direction to the supervision activities provided by the nurse taking over. Finally, problems yet to be regulated were more often tackled by the experts ( $40 \%$ against $15 \%$ in the case of novices and $20 \%$ in the case of experienced nurses). Experts seemed to anticipate regulation of problems af- 
fecting the patient's condition, above all based on clinical signs and behaviours. Therefore the regulation procedures to be carried out could be discussed during interaction during the handover.

As a summary, an analysis of the contents of oral handover enabled us to highlight its use as a pragmatic exchange concerning the development of the patient's condition based on indicators that were specific to the nurses concerning clinical signs and variations in behaviour. One of the issues of the handover has to do with the management and resolution of problems and regulation yet to be carried out. It would be interesting, but outside the quantitative limits of a single article, to deepen the types of problem regulated and those left unregulated, comparing them for example with the data from the analysis of the previous activity (step 1).

To what extent would information relevant for supervising a patient's condition, recorded during oral handover (clinical signs, behaviours, problems to be regulated) be present in targeted handover, and in what way? What information in addition to the oral handover, or subtracted from it, would be contained in the written handover documents? How were targeted handover documents produced and used in comparison with oral information? This is the subject of the analysis that follows, focussing on written handover documents.

\section{3.- Phase 3 - Targeted written handover documents}

We analysed the 70 written handover documents. A series of examples of these written handovers is supplied in figure 2. Initially, we will present the results of the analysis of the written documents themselves, then secondly, we will look at data originating from the verbal protocols we collected concerning the way these documents are written up.

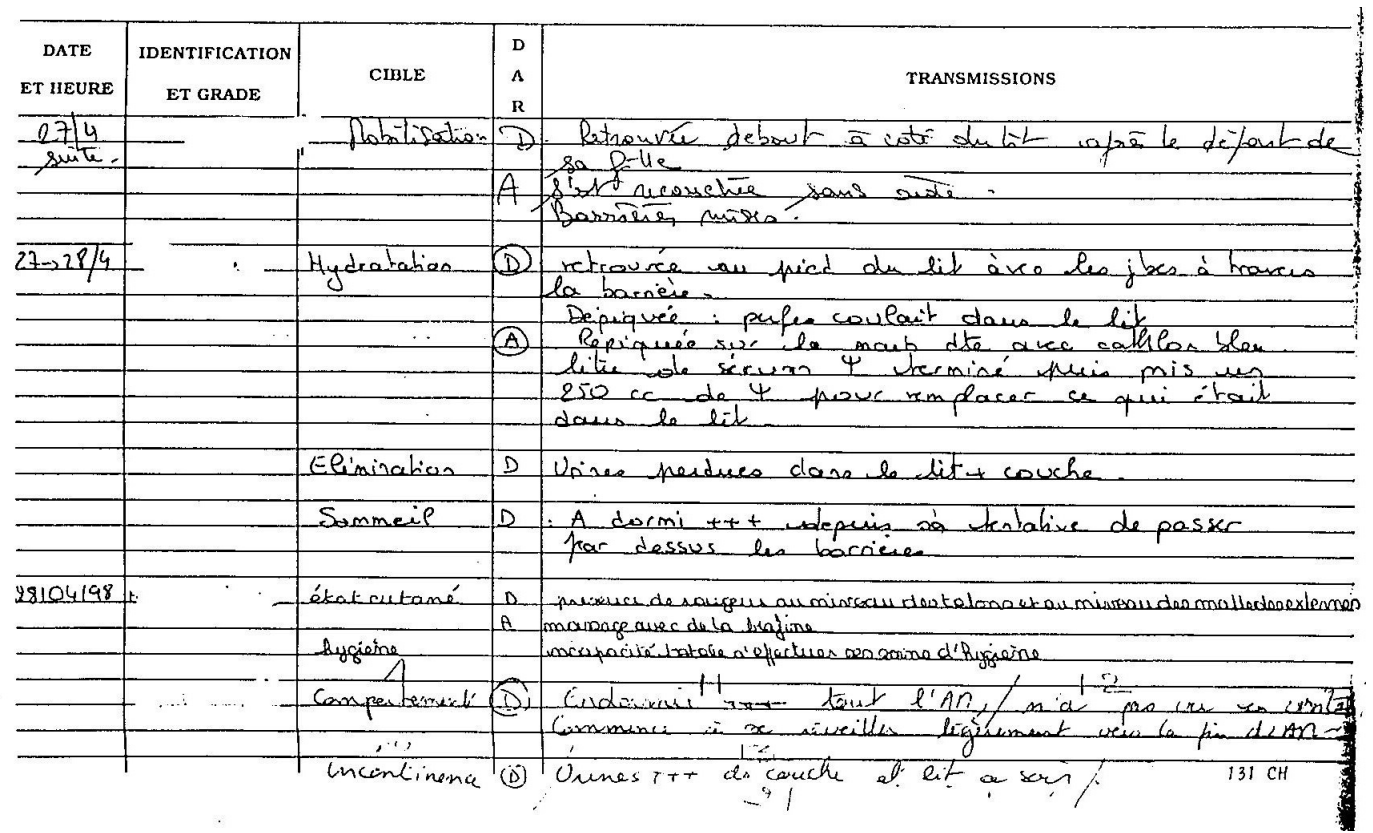

Figure 3 - Example of a written targeted handover form used for the shift change

\subsection{1.- Sorting information contained in the written handover document and using the DAR format}

We studied each handover document according to the presence of the prescribed elements: the presence of a target and sorting of information in DAR format to start with, followed by an analysis of the type of targets and the written structure. We thus processed 115 targets, as shown in table 5. 


\begin{tabular}{|c|c|c|c|c|c|c|}
\hline Sort & Data & DA & Non-classified & DAR & R & DARA/DRA \\
\hline $\mathbf{\%}$ & 26 & 23 & 20 & 12 & 12 & 7 \\
\hline
\end{tabular}

Table 5 - Distribution (in \%) of targets according to their structure (Data, Results, Data + Actions, Data + Actions + Results, Non-classified, Mixed)

We observed that only $12 \%$ of handovers followed the instructions for writing them up in DAR format, $27 \%$ were classified according to structures that did not correspond to the instructions relating to written scoring, and it was data above all that predominated. It was not always easy to distinguish the data from the results. In our classification, the result corresponded to explicit information concerning the effect (during the current shift) of an action undertaken concerning a parameter (behavioural or physiological). An item of data corresponded to information preceding the action. In summary, at first sight, the DAR structure seems badly suited to professionals' current written handover activity, or at least, difficult to use spontaneously.

In order to deepen these results, we broke down the development of 115 targets into statements. A statement corresponded to a coherent proposition and/or an expression smaller than a proposition but containing a semantic unit. A statement corresponded therefore, to a functional unit of the written handover document. For example, the statement "it's not yet clear if she needs a transfusion or not" comprises several (two) propositions, while the statement "incontinent" really only constitutes one. But both these statements express a single functional unit of medical information for the handover. By using this breakdown, we recorded 354 statements covering 115 targets found in the 70 written handover documents (corresponding to situations observed during the analysis of prior work), that is an average of 5 statements per handover (that is per patient) and three statements per target.

The distribution of statements according to the Data or Actions or Results criteria showed that information concerning data predominated (44\%) compared with actions $(21 \%)$ or results $(15 \%)$. There remained $20 \%$ of statements that were impossible to classify within these three categories. Data seemed therefore to constitute the informational basis for the change of shift.

\subsection{2.- The nature of the targets}

Out of 70 written handover documents, $97 \%$ included one (or more) targets. The average number of targets per patient came to 1.6 (a minimum of 1 and a maximum of 5 targets for a single patient). This result means that the nurses who took part in the study were to a significant extent committed to using the new format written handover document.

Recurring targets, common to the three departments, were few in number ("infectious risk, behaviour, pain, elimination, examination, admission, discharge, prognosis"). There were a few more that were common to two departments ("mobilisation, hyperthermia, cutaneous injury, blood pressure, nutrition, respiration, monitoring, haemo-dynamics"). Targets specific to one department had to do with the specific nature of the pathologies treated in the medical department concerned (in the medical department: "confusion, dyspnoea", for example; - in nephrology: "dialysis education", for example; - in neurosurgery: "head bandage", for example).

Taking this disparity into account, we classified the targets according to themes. We analysed a sample of 1258 targets. This sample corresponded to the body of 70 written handover documents written up on the day the nursing activity was observed, to which were added the written handover documents from the day the patient was admitted up until the day of the observation. The classification criteria used, as well as the distribution of the targets according to each category are shown in table 6. 


\begin{tabular}{|l|c|}
\hline \multicolumn{1}{|c|}{ Criteria used for categorising targets } & Distribution in \% \\
\hline $\begin{array}{l}\text { Physiology (concerning a physiological event that occurred: nasal discharge, } \\
\text { dyspnoea, vomiting, headaches, etc.). }\end{array}$ & 57 \\
\hline Hospitalisation phase (admission, consultation, discharge, report, block, etc.). & 12 \\
\hline $\begin{array}{l}\text { Technical actions carried out/to be carried out (mobilisation for treatment, head } \\
\text { bandage, etc.). }\end{array}$ & 10 \\
\hline Psychology (confusion, refusal of treatment, etc.). & 9 \\
\hline Patient's pathology (renal failure, diabetes, etc.). & 5 \\
\hline Technical equipment (for drips, implantable chamber, etc.). & 3 \\
\hline Treatment in progress (fraxiparine injection, dialysis education, etc.). & 3 \\
\hline Miscellaneous & 1 \\
\hline
\end{tabular}

Table 6 - Distribution (in \%) of types of targets according to category themes

It can be observed that it is first of all new physiological events, then hospitalisation phases, technical actions and finally psychological aspects that constitute the contents of the targets. What functions does this information serve for the handover? What indication does it give concerning regulation of the patient's care after the handover? In order to clarify this aspect, we carried out two types of analysis. In the first, we focussed on the syntactical and verbal forms used by professionals in writing up their reports. In the second, we systematically looked for traces of nursing activity (diagnosis, regulation, recommendations). This analysis seemed to us to be suitable for establishing indicators of the activity, diagnosis and regulation proposed.

\subsection{3.- Function of targeted handover for the change of shift.}

The purpose of this analysis is to clarify the functions of the information contained in the written handover documents.

By initially studying the syntax, we are able to distinguish three categories. The first, subject - verb - complement ( $s v c$ ), corresponded to canonical syntax of how the sentence was written. The second has a relatively abridged form, verb - complement (sv). Finally the third constituted a limited syntactical restriction limited to word order (wo). This last category not only corresponded to the use of elliptical forms, but also to a restricted syntax similar to the restricted language described by Falzon for oral handover $(1989,2004)$. The distribution of statements in the written handover documents according to these categories showed that the $s v c$ structure represented $22 \%$ of the statements, the $s v$ structure $43 \%$, and the wo structure $35 \%$. This data indicated that language of the operative type, well-known in oral handover, (Falzon, 1989, 2004) was here used in writing, often restricted to the word order: "red sacrum, lateralisation and friction, stools at 20.00"). Furthermore, a large proportion of technical words were added to these economical, selective and effective restrictions used between experts.

As far as verbal forms are concerned, in second place, we divided up each statement according to the tense used for its formulation. The results of this division indicated that the past tense was used mostly ( $47 \%$, past tense, past participle), followed by the present tense $(23 \%)$ or non-verbal phrases $(29 \%)$. The use of the future tense is much rarer (6\% for the simple future, $6 \%$ for the imperative). This result suggests that written information was directed towards past or present actions (59\%) and/ or data, but much less often towards actions to be carried out (6 to $12 \%)$, anticipated actions, that is to say, regulations to be carried out and problems to be regulated. Of course, past information is also essential for taking decisions determining future action. However, these latter decisions constituted, 
as we showed in our analysis of oral handover, indicators of patient care given by professionals.

In third place, what trace of the traces of patient care activity could be found in written handover documents, firstly in respect of the choice of target? We were able to note two types of targets. The first related to the use of categories originating from a theoretical model traditionally taught during nursing training: "the theory of need". This model uses a categorisation organised in terms of general physiological and psychological vital functions like "respiration", "elimination", and "communication" for example. The written documents presented in figure 2 contain this listing: "mobilisation, hydration, elimination, sleep". This type of more formal target does not on the face of it (and on its own) supply information concerning the state or development of the patient's condition. The second type of target has more to do with a variable describing the evolution of the patient's condition: "fatigue", "lack of appetite", "hypoglycaemia". This distinction between these two types of target can apply to both physiological and psychological targets. As the data in table 7 shows, need type targets seem to dominate in the physiological domain, variables indicating condition being massively reserved for the psychological domain.

\begin{tabular}{|l|c|c|}
\hline & Need type target & Condition variable type target \\
\hline Physiological domain & 55 & 45 \\
\hline Psychological domain & 2 & 98 \\
\hline
\end{tabular}

Table 7 - Distribution (in \%) of the need type or condition type target types according to their domain, physiological or psychological

Furthermore, it appeared that in $80 \%$ of the written documents analysed, this formulation of targets using the "needs" listing could generate semantic ambiguity concerning coherence between the information provided by the target and that provided by the data. Let's take a few examples. In the following document: "mobilisation (target). After getting out of the chair, breathing better but suffering from very bad backache (data)", one could think that the term "mobilisation" relating to a need, is ambiguous, or unsuitable for designating important data concerning the patient's condition (corresponding to the target according to DAR format) relating to breathing difficulties and not to the mobilisation action undertaken. The same is true for the two following examples (taken from figure 2): in the written document "Mobilisation (target). Found standing beside his bed after his daughter had gone (Data)", the crucial information "found standing" is not defined precisely by the target. In the written document "Hydration (Target). Found at the foot of the bed leaning on the barrier. Having come out, the drip was running into the bed (Data) ", the information described by the data is also reflected ambiguously in the target "hydration" (which corresponds to a general need for water). This type of ambiguity could be interpreted as being due to the nurses having difficulty in finding or deciding on a target. This would be rather surprising in the case of expert professionals. An alternative hypothesis seems plausible to us: it could turn out to be very difficult to describe a target reflecting changes expressed by clinical signs and/or behaviours using a generic or single term. In this case, the formulation in generic terms originating from the "theory of needs" would correspond to an adaptive use, taken from this medical register, thus corresponding to an instrumental borrowing of language (Rabardel, 1995) in order to describe problems (or their consequences) occurring in the patient: problems linked to mobilisation, problems linked to hydration, etc. In short, by using this type of formulation, are professionals trying to adapt to the instructions? It could also be that professionals were not able to construct a clear and precise representation of the notion of the target prescribed in the DAR format. These last two alternatives would reflect ambiguity in the instructions themselves. Finally, problems of consistency between targets and data were much more frequent when the target designated a need $(87 \%)$ than when the target was formulated in terms of a condition variable $(52 \%)$ $\left(\mathrm{Chi}^{2}=7.63, \mathrm{p}<.01\right)$. Thus the condition variable takes better account of nursing activity. But above all, the ambiguities in reference terminology that we have just raised bear witness to the difficulty of using the DAR format. The structural constraints of this format have, it seems, led to a transformation of written documents that is hardly compatible with the functional representations in terms of clinical 
and psychological signs that constitute patient care indicators for nurses.

Traces of care were also shown in the type of information developed. The distribution of the different types of themes developed in handover documents based on targets, came close to that recorded for oral handover, as shown in table 8.

\begin{tabular}{|l|c|c|}
\hline \multicolumn{1}{|c|}{ Reference themes } & $\begin{array}{c}\text { Oral } \\
\text { handover }\end{array}$ & $\begin{array}{c}\text { Written } \\
\text { handover }\end{array}$ \\
\hline Medical prescription & 34 & 44 \\
\hline Behaviour & 18 & 20 \\
\hline Clinical signs & 16 & 20 \\
\hline Diagnosis & 9 & 6 \\
\hline Reason for admission & 6 & 0 \\
\hline Identity & 4 & 0 \\
\hline $\begin{array}{l}\text { Pathologies (on dis- } \\
\text { charge) }\end{array}$ & 4 & 0 \\
\hline Non-prescribed actions & 4 & 8 \\
\hline General organisation & 4 & 2 \\
\hline
\end{tabular}

Table 8 - Division (in \%) into themes in the case of oral and written handover

We again observed great sensitivity to expertise in the distribution of themes. Behaviours, clinical signs and actions decided upon (non-prescribed) appeared higher in the two most experienced groups (respectively: $63.5 \%$ for the experts, and $66 \%$ for the experienced) than among the novices $(36.5 \%)$. The trend was reversed in the case of medical prescription which appeared more among the novices $(50 \%)$ than among the experts nurses $(27.5 \%)$ or experienced nurses $(20 \%)$.

\subsection{4- The disappearance of regulation during written handover}

One of the functions of oral handover concerned regulating problems, in particular problems that had not been regulated or remained to be regulated (51\% of problems). We noted regulations carried out exclusively in the written documents. Thus, written handover documents contained no explicit reference to problems to be regulated and problems occurring with regulation. Paradoxically, this information directly linked to patient care and to the anticipation of risks was subject to filtering between the written and the oral handover stages. Certain types of regulation, which may have been discussed during oral handover, may not have been so easy to explain in the written record, due for example to uncertainties with regard to the situation to be regulated and also due to a possible lack of reliable information concerning a regulation currently in progress. Deeper examination of the data resulting from an analysis of previous care activity that we recorded could provide relevant information in order to find the reasons for this disappearance of regulation.

In summary, we observed that current written handover documents in DAR format were not suited to nursing staff's needs. They did contain, however, a large number of the traces of specific patient care activity given by nurses: changes in clinical signs, behaviours, non-prescribed independent actions. But major filtering had taken place with regard to regulation, a major issue at oral handover stage. In addition, the information described was relatively different according to the level of expertise. Finally, the two types of handover, written and oral, did not seem to fulfil the same function. The written handover did not contain the same information as the oral handover and did not necessarily concern the same recipient as the oral handover. 


\subsection{5.- Sorting criteria in written handover}

What are the cognitive criteria involved in the type of selection carried out for the written handover? This is what we will tackle next by looking at, as a last analysis, the results obtained based on the verbal protocols of each nurse concerning each of their written handover documents from the previous cycle.

During a task involving individual explanation (Bisseret Sébillotte, \& Falzon, 1999), each nurse had both the latest written handover documents as well as a transcription of the reference knowledge database previously analysed for each patient. Each nurse had to answer two questions (standardised) for each handover: "How did you select (choose) the information to include in the handover?" (and so on for each handover) and "how did you decide not to include (choose) certain information?" The purpose of this task was to collect the "explicit" rules used during the writing phase itself. For each handover, we first looked at the sorting mechanisms explicitly referred to that were common to the three groups of nurses and to each level of expertise. Then we made a more precise distinction between the positive sorting factors corresponding to information that was retained, and finally the negative sorting factors corresponding to information that was discarded. In each case, a single explicit reference to the criteria was sufficient for it to be retained.

In the first place, all the professionals indicated the existence of a phase of recall from memory, accompanied subsequently by other actions. More specifically, the experts acknowledged using the following indicators: "recalling care information from memory", "reading previous handover documents" and "interactions with the patient". The novices reported: "recalling information from memory", "information presents itself in the form of pictures". Experienced staff indicated: "recalling information concerning care from memory", "reading previous handover documents". During this phase, common to all, it can be added that the novices were more trying to recall information based on care given ("images"), the experts basing their evaluation more on information resulting from supervision of the patient's condition.

In second place, we recorded the criteria used for selecting the more specific information that the nurses acknowledged using during the handover writing phase itself, according to each level of expertise. The results are given in tables $9 \mathrm{a}$ (information retained) and $9 \mathrm{~b}$ (information discarded).

\begin{tabular}{|c|c|c|}
\hline Novices & Experienced & Expert \\
\hline $\begin{array}{l}\text { Declared aim of the sort } \\
\text { - Doctor's prescription (to be } \\
\text { carried out). } \\
\text { - Don't repeat the information. } \\
\text { - To incorporate the "nurses' di- } \\
\text { agnosis" }\end{array}$ & $\begin{array}{l}\text { Declared aim of the sort } \\
\text { - } \quad \text { To note and categorise difficul- } \\
\text { ties. }\end{array}$ & $\begin{array}{l}\text { Declared aim of the sort } \\
\text { - To choose memorised knowl- } \\
\text { edge concerning the patient } \\
\text { concerning the development of } \\
\text { the patient's condition. }\end{array}$ \\
\hline $\begin{array}{l}\text { Selection criteria } \\
\text { - } \quad \text { Patient's problem (initial diag- } \\
\text { nosis). } \\
\text { - } \quad \text { Appearance of a problem that } \\
\text { day. } \\
\text { - } \quad \text { Change during the shift. } \\
\text { - } \quad \text { Exchange with the doctor with } \\
\text { regard to the prescription. } \\
\text { - Shift tasks not carried out with } \\
\text { regard to the prescription. } \\
\text { - Measured condition (sheets) of } \\
\text { the pathology. }\end{array}$ & $\begin{array}{l}\text { Selection criteria } \\
\text { - Non-targeted information in } \\
\text { the form of a report (forms } \\
\text { etc.). } \\
\text { - Change in a parameter (includ- } \\
\text { ing outside the initial diagno- } \\
\text { sis). } \\
\text { - Supplementary information as } \\
\text { compared with the previous } \\
\text { target (measurements, clinical } \\
\text { signs) in the form of results. }\end{array}$ & $\begin{array}{l}\text { Selection criteria } \\
\text { - } \quad \text { Change in clinical data as com- } \\
\text { pared with the last shift. } \\
\text { - Major changes in the prescrip- } \\
\text { tion involving a vital risk (care } \\
\text { by nurses from the next shift). } \\
\text { - Information signalling doubts } \\
\text { concerning the effect of the } \\
\text { treatment. } \\
\text { - Results of examinations car- } \\
\text { ried out. } \\
\text { Independent actions carried } \\
\text { out. }\end{array}$ \\
\hline
\end{tabular}

Table 9a - Criteria for selecting information to write up according to level of expertise. 


\begin{tabular}{|c|c|c|}
\hline Novices & Experienced & Expert \\
\hline 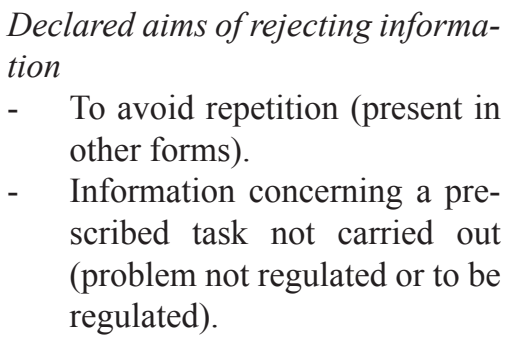 & $\begin{array}{l}\text { Declared aims of rejecting informa- } \\
\text { tion } \\
\text { - } \quad \text { To avoid repetition (present in } \\
\text { other forms). } \\
\text { - } \quad \text { Information concerning a pre- } \\
\text { scribed task not carried out } \\
\text { (problem not regulated or to be } \\
\text { regulated). }\end{array}$ & $\begin{array}{l}\text { Declared aims of rejecting informa- } \\
\text { tion } \\
\text { - To avoid repetition (present in } \\
\text { other forms). } \\
\text { - Information concerning a pre- } \\
\text { scribed task not carried out } \\
\text { (problem not regulated or to be } \\
\text { regulated). }\end{array}$ \\
\hline $\begin{array}{l}\text { Specific criteria } \\
\text { - Problem of the day already } \\
\text { known. } \\
\text { - "Life habits not communicable } \\
\text { in DAR". }\end{array}$ & $\begin{array}{l}\text { Specific criteria } \\
\text { - Knowledge concerning the pa- } \\
\text { tient governing the choice of a } \\
\text { relationship strategy. } \\
\text { - Actions to be carried out dur- } \\
\text { ing the next shift don't depend } \\
\text { on the medical prescription. }\end{array}$ & $\begin{array}{l}\text { Specific criteria } \\
\text { - Doubt concerning a problem } \\
\text { involving care different from } \\
\text { that prescribed. } \\
\text { - Knowledge concerning the pa- } \\
\text { tient governing the choice of a } \\
\text { relationship strategy. } \\
\text { - Patient discourse not specific } \\
\text { enough. } \\
\text { - Forgotten. } \\
\text { - Non-prescribed action. }\end{array}$ \\
\hline
\end{tabular}

Table $9 \mathrm{~b}$ - Criteria for rejecting information during the write-up phase

As far as the information retained is concerned (table 9a), it appeared that novice nurses were more likely to select information targeted on the prescribed task: medical prescription, repeated tasks, shift tasks not carried out. Nurses with a little more experience mainly based their selection on choosing information missing from the previous handover or from other sheets that had already been written up. The experts did the same to a certain extent. But the latter mainly seemed to select relevant information from representations memorised during previous shifts and above all the actions carried out during the care cycle. This information concerned a model of the change of condition of the patient constructed through the supervision activity, based on clinical and behavioural signs that were explicit, precise and had to do with the risk dimension for the patient: a change in clinical data, changes in the prescription, information signalling doubts concerning the effects of the treatment.

As far as criteria used for rejecting information are concerned (table 9b), we note the appearance of redundant information for the three sub-groups, but also and above all actions or problems to be carried out or not carried out. For the experts, it seemed that as soon as a doubt arose (concerning the meaning of clinical signs), the information was not transcribed. Thus, written handover documents did not explain the situations to be regulated, situations that had not been regulated or for which there was too much doubt. Rather, it was situations concerning activities to resolve problems which were at the centre of exchanges during the oral handover.

\section{4.- Discussion and conclusion}

During an approach comparing three phases of nursing activity comprising the care activity, then successively oral and written handover, we carried out an ergonomic evaluation of the use of a newly prescribed written handover format: targeted handover documents in DAR format. This study covered nine nurses - experts, experienced and novices - working with 70 patients in three comparable medical departments. Analysis showed that, on the one hand, the form of these written handovers only corresponded to the DAR structure to a minor degree, and on the other hand, that current regu- 
lation activities or those posing a problem (doubts concerning a sign, regulation problems), and particularly important for the next shift, had been discarded from the written documents, although they were most often the issue discussed during oral handover. Thus the dialogue at oral handover and the traces left by the written handover played different roles in patient care during the different shifts. At the change of shift, oral and written handover contained traces of supervision of patients' condition by the nurses. This supervision activity was based on the selection, transmission and discussion of specific indicators: modifications to, or changes in, clinical signs and behaviours. These indicators, sensitive to the level of expertise, permitted the prevention and regulation of problems and therefore of possible risks.

Based on the results of data collected during the three phases of the analysis we carried out, we prepared a summary in the form of a model of the written handover activity studied here. This model was inspired on the one hand by models of written production prepared in cognitive psychology which appeared extremely compatible with our results (Fayol, 1997) and on the other hand, by the results of our analysis of written handover notes. The model proposed in figure 4 comprises three stages. During the first, the nurse's goal is to choose a target. To do this, he/she recalls relevant and pertinent information from memory concerning the patient's development and the activities carried out during the previous period. This recall may take place in parallel with another sort of processing that is more akin to sorting information by several criteria. In fact, an item of data or a significant new action needs to be chosen as a target for regulating the patient's care, by comparing it not just with previous written documents, but also with "internal standards of acceptability", in particular in the case of a non-regulated problem (knowing that the information concerning these regulations may be transmitted orally). This task implies decision making activity. This first stage leads to the preparation of a multi-dimensional conceptual representation of the elements chosen, corresponding to a potential target.

The second stage is a phase in which information is structured and organised into Data and/or Action and/or Results, in an attempt to update a textual structure that is compatible with the required principles.

The last stage corresponds to putting the information into words (vocabulary, formulation, including implicit or coded forms). As has been shown (in other fields of writing) by the results of works of experimental psychology in the area of written production (Bock \& Cutting, 1992 ; Bonnin, \& Fayol, 1996 ; Fayol, 1997 ; Alamargot, 2003), the handover "bottleneck" represented by the need to transform descriptions resulting from care activity into DAR format (second stage) could prove to be difficult and costly for the operator. Nurses could find it necessary to look for supplementary clarification requiring new interaction with the representation resulting from the activity, that is to say, prior knowledge concerning the patient and the actions carried out. Such feedback (cycles) is represented in figure 4 by the model's vertical double arrows. The eventual cost may pose a problem for the actual use of the prescribed structure, over the long term, during care activity. Over time, the risk of the spontaneous abandonment or at least the transformation of this system of recording information is to be anticipated. What is the gain for the operator in using this structure, in terms of the written document produced and its use?

Constraints imposed by the writing process must not become the priority task for the operator as compared with the task of communicating relevant information concerning the monitoring of changes in the patient's condition, which becomes secondary. For example, for an important item of information (a warning sign) to be rejected because there is no place for it in the structure. 


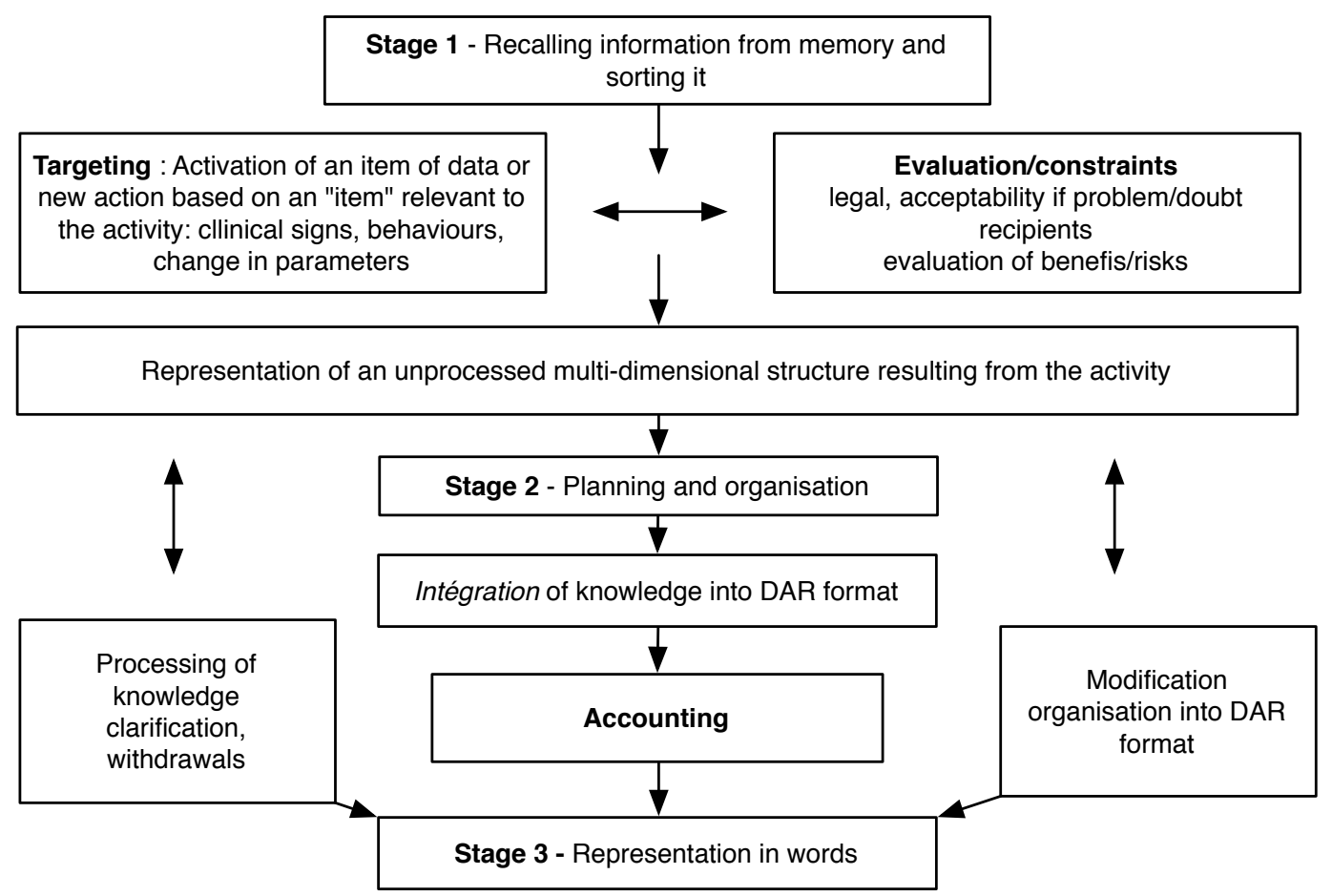

Figure 4 - A model of how written handover documents are produced in Data, Actions and Results format

Our objective was to evaluate the ease of use of the new written format, the targeted handover document in DAR format, in the context of its use by nurses in the written handover process. This new tool had been suggested, then implemented, by the hospital in the context of seeking accreditation for the establishment. The benefit expected from this new instruction from the managers was to enable better patient care through the selection of aspects that were significant for the development of the patient's condition, to provide traceability with respect to handling of the patient, to capitalise on written, reliable and practical information in providing continual care. However no prior analysis of the oral and written handover activity and of nursing staffs' existing skills in this domain was planned or carried out by the institution before this new tool was introduced. Such an analysis would have led to a better understanding of how the handover operated before the introduction of the tool for "improving" written documents. Faced with the objective difficulties linked to the use of targeted handovers, professional training was envisaged and was the purpose of the request made to us. However our analysis revealed that this teaching response was not the first issue that needed dealing with. In fact, we showed that the tool recommended was not suited to the professionals' needs. In fact, far from being a "cognitive tool" to help with the activity of writing up written handover documents (Rogalski, 2001), it appeared that, in its present form, the Target + DAR format was restricting, not used very much, not really suited to nurses' needs and difficult to use. The processes of filtering information between activities carried out before the oral handover and the written handover that we analyse here, show that the oral and written handover processes do not contain the same traces and do not play the same role in patient care. The issues in the oral handover do not just seem to communicate new information concerning patients but constitute exchanges concerning problems in the process of being regulated or which have not been regulated and therefore prevent risks for the patient. Exchanges concerning problems could constitute real tools for patients' continuing care. However, with the introduction of the new standards for written records, references to them disappeared totally from the written traces. Even if these written handover documents preserve traces of nurses' supervision activity via descriptions of clinical signs and patients' new behaviours, they are limited to a description of problems that have been regulated. One could be forgiven for asking, to 
what point has the introduction of the new format for written documents degraded existing practices for written handover?

If optimisation of the organisation and accuracy of written handovers seems necessary, and above all desired by the professionals working in the institution, it would appear that the structure of such a written document needs to be in keeping with the structure of the nurses supervision activity and the organisation of the operative representations resulting from this activity. Furthermore, the choice of written structure, as that in relation to the criteria governing content (pertinence) and accuracy of information, could be the subject of collaborative design between the hospital's professionals and managers, in the context of the development of competencies in the domain of the shift change. It would appear especially necessary to find out nurses' precise and actual needs in order to optimise written documents. This would seem particularly useful for novice nurses as shown by our systematic comparison between the three levels of expertise.

From this perspective, a deeper analysis of "spontaneous" written handovers by nursing staff needs to be carried out for the purpose of gaining a better understanding of how they work, outside the framework of any changes to the format. The results presented earlier also indicate that it would appear necessary to carry out work to define the nature and form of the written documents expected. This work could usefully be directed towards formats closest to the "dynamic operative" representations of a patient's condition constructed by nursing staff while providing care. In fact, these representations appear to be "multi-dimensional" for example, at the same time as being "objective" or measurable clinical signs, they incorporate the patient's "experience". Finally, a study concerning the contents of the information in relation to its reliability could be usefully undertaken. In fact, do not shift changes and handover (written or oral) constitute an extremely critical part of the task prescribed to the incoming operator by the outgoing operator, and constitute an activity that is crucial for the continuity of care?

\section{REFERENCING}

Boucheix, J.-M \& Coiron, M. (2008). Analysis of the written handover process during shift changes within the hospital: an ergonomic evaluation of the use of a new writing format. @ctivites, 5 (1) pp. 103-125, http://www.activites.org/v5n1/v5n1.pdf

\section{REFERENCES}

Alamargot, D., \& Dansac, C. (2003). Composer une consigne à partir de sources: ce que nous indiquent les activités graphiques et oculaires des rédacteurs. Journées d'études, Production, compréhension et usages des écrits techniques au travail. MSHS, Toulouse, 19-20 juin.

Bisseret, A., Sébillotte, S., \& Falzon, P. (1999). Manuel pratique pour l'analyse des activités expertes. Toulouse: Octarès.

Bock, J.K., \& Cutting, J.C. (1992). Regulating mental energy: performance units in language production. Journal of memory and language, 31, 99-127.

Bonnin, P., \& Fayol, M. (1996). L'étude en temps réel de la production du langage écrit: Pourquoi et comment. Etudes de Linguistique Appliquée, n¹01, 8-19.

Boucheix, J.M. (2003). Ergonomie et formation: approche d'ergonomie cognitive de l'apprentissage professionnel. Psychologie Française, 48-2, 43-56.

Boucheix, J.M. (2005). L'accueil, orientation courtoise ou activité de résolution de problèmes, In M. Cerf, \& P. Falzon, Relations de service: Travailler avec le client (pp.87-111). Paris: PUF.

Bourdin, B. (1994). Coût cognitif de la production verbale. Etude comparative orallécrit chez l'enfant et l'adulte. Thèse pour le doctorat en psychologie de l'Université de Bourgogne.

Boutet, C. (1995). Les écrits professionnels. Sociologie du Travail, 4, 25-52. 
Cellier, J.M., De Keyser, V., \& Valot, C. (1996). Le temps dans la conduite des systèmes dynamiques. Paris: PUF.

Cosnier, J., Grosjean, M., \& Lacoste, M. (1993). Soins et communications, Lyon: PUL.

Cerf, M., \& Falzon, P. (2005). Ergonomie de la relation de service: travailler avec le client. Paris: PUF.

Cerf, M., Valléry, G, \& Boucheix, J.M. (2004). Les situations de service: enjeux et développement. In P. Falzon (Ed.), Traité d'Ergonomie (chapitre 34, pp. 565-581). Paris: PUF.

Davillerd, C., \& Grusenmeyer, C. (1994). La relève de poste: une période spécifique de travail collectif. Actes du XXVIIéme Congrès de la société d'ergonomie de langue Française (pp. 143-151). Toulouse: Octarès.

Errard, G., Kostulski, K., \& Trognon, A. (1996). Le dossier de soins : instrument de communication. A. A. R. C. $H$.

Falzon, P. (1989). Ergonomie cognitive du dialogue. Grenoble: PUG.

Falzon, P. (2004). Traité d'Ergonomie. Paris: PUF

Fayol, M. (1997). «Des idées au texte: psychologie cognitive de la production écrite » Paris: P.U.F.

Giboin, A. (2004). La construction des référentiels communs dans le travail coopératif. In J.M. Hoc, \& F. Darses (Eds.). Psychologie ergonomique: tendances actuelles (pp. 119-139). Paris: PUF.

Grosjean, M., \& Lacoste, M. (1999). Communication et Intelligence Collective: Le Travail à l'Hôpital. Paris: PUF.

Grusenmeyer C. (1995). Interaction langagière et représentation mentale partagée. Une étude de la relève de poste. Psychologie Française, 40, 47-59.

Grusenmeyer C. (1996). De l'analyse des communications à celle des représentations fonctionnelles partagées. Thèse de Doctorat de Psychologie Cognitive, INRS, A.8/1. 008.

Grusenmeyer, C., \& Trognon, A. (1996). Strutures of natural reasoning within functional dialogues. Pragmatics \& Cognition, 4 (2), 305-346.

Hayes, J.R ., \& Nash, J.G. (1996). On the nature of planning in Writing. In C.M. Levy, \& S. Randsell (Eds.), The science of writing (pp. 29-55). Mahwah, N.J.: Lawrence Erlbaum Associates.

Heurley, L. (1994). Traitement des textes procéduraux. Etude de psycholinguistique cognitive des processus de production et de compréhension chez des adultes non experts. Thèse pour le doctorat de Psychologie, Université de Bourgogne.

Hoc, J.M. (1996). Supervision et contrôle de processus. La cognition en situation dynamique. Grenoble: PUG.

Montmollin de, M., (1986). L'intelligence de la tâche. Bern: Peter Lang.

Leplat, J. (1997). Regards sur l'activité en situation de travail. Paris: PUF, Le Travail Humain.

Levelt, W.J.M. (1989). Speaking: From intention to articulation, Cambridge: MA, MIT Press.

Levelt, W.J.M., \& Maassen, B. (1991). Lexical search and order of mention in sentence production. In W. Klein, \& W.J. levelt (Eds.), Crossing boundaries of linguistics (pp. 109-123). Dordrecht: Reichel.

Pastré, P. (1997). Didactique professionnelle et développement. Psychologie Française, 42, 89-10.

Rabardel, P. (1995). Les hommes et les Technologies. Approche Cognitive des Instruments Contemporains. Paris: Armand Colin.

Raufaste, E. (2001). Les mécanismes cognitifs du diagnostic médical. Optimisation et expertise. Paris: PUF.

Rogalski, J. (2001). Connaissances opérationnelles, compétences. In J. Leplat, \& M. de Montmollin (Eds.), Les compétences en ergonomie (pp. 250-275). Toulouse: Octarès Editions. 
Rogalski, J. \& Samurçay, R. (1994). Modélisation d'un savoir de référence et transposition didactique dans la formation des professionnels de haut niveau. In G. Arsac, Y. Chevallard, J.L. Martinand, \& A. Tiberghien (Eds.). La transposition didactique à l'épreuve (pp. 35-71). Grenoble: La Pensée Sauvage Editions.

Vallery, G., Boucheix, J.M., Leduc, S. \& Cerf, M. (2004). Analyser les situations de service: questions de méthodes. In M. Cerf, \& P Falzon (Eds.). Situations de service: travailler dans l'interaction, (pp. 21-40). Paris: PUF. 